\title{
Superabsorbent Polymer as Nanoreactors for Preparation of Hematite Nanoparticles and Application of the Prepared Nanocatalyst for the Friedel-Crafts Acylation
}

\author{
Hamdollah Saeidian, ${ }^{a}$ Firouz Matloubi Moghaddam, ${ }^{* a}$ Ali Pourjavadi, ${ }^{a}$ Shahram Barzegar, ${ }^{a}$ \\ Rouhollah Soleyman ${ }^{a}$ and Abouzar Sohrabi ${ }^{b}$ \\ ${ }^{a}$ Department of Chemistry, P.O. Box $11155-9516$ and ${ }^{b}$ Institute for Nanoscience \& Nanotechnology, \\ P.O. Box 11155-8639, Sharif University of Technology, Tehran, Iran
}

\begin{abstract}
Descrevemos a síntese de nanopartículas $(30 \mathrm{~nm})$ puras de $\alpha-\mathrm{Fe}_{2} \mathrm{O}_{3}$ empregando um nanopolímero superabsorvente (SANP), por decomposição térmica. $\mathrm{O} \alpha-\mathrm{Fe}_{2} \mathrm{O}_{3}$ sintetizado foi caracterizado por difração de raios X (DRX), infravermelho com transformada de Furrier (IV-TF), microscopia eletrônica de transmissão (TEM) e termogravimetria (TG). A aplicabilidade deste material nanoestruturado foi verificada por seu efeito catalítico na acilação de Friedel-Crafts.
\end{abstract}

The synthesis of pure $\alpha-\mathrm{Fe}_{2} \mathrm{O}_{3}$ nanoparticles (30 nm) using a superabsorbent nanopolymer (SANP) by the thermal decomposition is reported. Synthesized $\alpha-\mathrm{Fe}_{2} \mathrm{O}_{3}$ nanoparticles were characterized by X-ray diffraction (XRD), Fourier transform infrared spectroscopy (FT-IR), transmission electronic microscopy (TEM) and thermogravimetric analysis (TG) techniques. The applicability of this nanostructure material was assessed by its catalytic effect on the FriedelCrafts acylation.

Keywords: superabsorbent nanopolymer, $\alpha-\mathrm{Fe}_{2} \mathrm{O}_{3}$ nanoparticles, thermal decomposition, Friedel-Crafts acylation

\section{Introduction}

Hematite $\left(\mathrm{Fe}_{2} \mathrm{O}_{3}\right)$ has drawn enormous attention due to a wide range of applications such as pigments, catalysts, drug delivery, contrast agents in magnetic resonance imaging (MRI), hyperthermia, gas sensors and biosensors. ${ }^{1-7}$ However, these applications are still subject to many constrains, such as particle size, size monodispersity, morphology, biocompatibility and stability. Controlling the size and shape of materials are two critical parameters. They could have strong influences on their chemical and physical properties. Developing new methods for the synthesis of nanomaterials as well as the modification of their size and morphology remains a great challenge. Many methods have been developed for preparation of nanosize materials with different morphologies and size distribution such as template method, sol-gel, microwave heating synthesis, pyrolysis, supercritical $\mathrm{CO}_{2}$ method, ultrasonic irradiation synthesis, solution-phase approach ${ }^{8-14}$ etc. In most of these approaches, nanoparticles tend to agglomerate due to large specific surface area and high surface energy. In order to improve size distribution and morphology of nanoparticles,

*e-mail: matloubi@sharif.edu without any agglomeration during the synthesis, magnetite nanoparticles coating with capping agent is required. Thermal decomposition of ion salts is one of the facile methods to produce nanosize materials, in which ion salt is coated by an appropriate coating agent, and then the thermal decomposition of coated ion salt could lead to nanomaterials. ${ }^{15-17}$ Following our research on nanoparticles synthesis and their applications in organic synthesis and polymer science, ${ }^{18-23}$ herein, we propose a facile thermal decomposition route to synthesize $\alpha-\mathrm{Fe}_{2} \mathrm{O}_{3}$ nanoparticles. The strategy in this study is the application of salep-g-poly acrylic acid (salep-g-PAA) acting as an inexpensive and available coating agent. ${ }^{24,25}$ The salep-g-PAA nanopolymer with hydroxide and carboxylic acid functional groups has a certain binding affinity to metal ions, which may control the size and morphology of $\alpha-\mathrm{Fe}_{2} \mathrm{O}_{3}$ nanoparticles without any agglomeration.

\section{Experimental}

\section{Apparatus and characterization}

X-ray diffraction (XRD) was preformed with a Siemens D5000 X-ray diffractometer using graphite- 
monochromatized high-intensity $\mathrm{Cu}-\mathrm{K} \alpha$ radiation $(\lambda=1.5406 \AA)$. Fourier transform infrared spectroscopy (FT-IR) was performed using a Nicolet (Magna 500). A JEOL JEM-2010 transition electron microscope (TEM) was used to determine the average of particle size and morphology of the powders on an accelerating voltage of $100 \mathrm{kV}$. The morphology of the dried superabsorbent nanopolymer was examined using a scanning electron microscope (SEM) (Philips, XL30) at $25 \mathrm{kV}$ after coating the samples with gold film. Thermal properties were studied through the thermogravimetric (TG) thermal technique (PL-1500). An atomic absorption spectrometer (Varian AA-5) was used for measurements of metal ion absorption. A Bruker (DRX-500 Avanes) NMR was used to record the ${ }^{1} \mathrm{H}$ NMR and ${ }^{13} \mathrm{C}$ NMR spectra.

\section{Preparation of the salep-g-PAA nanopolymer}

Salep (1.0 g) and distilled water $(40 \mathrm{~mL})$ were added to a three-neck reactor equipped with a mechanical stirrer. The reactor was placed in a thermostated water bath at $80{ }^{\circ} \mathrm{C}$ for $20 \mathrm{~min}$. After homogenizing the mixture, the monomer, acrylic acid (AA) (1.06 mol L-1 , 40\% neutralized) and the crosslinker, methylenebisacrylamide (MBA) $\left(5.2 \times 10^{-3} \mathrm{~mol} \mathrm{~L}^{-1}\right)$ were simultaneously added. The mixture was stirred for further $15 \mathrm{~min}$. Then, the ammonium persulfate initiator (APS) $\left(2.6 \times 10^{-3} \mathrm{~mol} \mathrm{~L}^{-1}\right)$ was added and the gel-like product was observed after about $20 \mathrm{~min}$. Finally, the reaction mixture was cooled to room temperature. The product was poured into $100 \mathrm{~mL}$ of ethanol (remained for $2 \mathrm{~h}$ ) and then scissored to small pieces. The solvent was decanted and then $100 \mathrm{~mL}$ of fresh ethanol was added. The product remained for $24 \mathrm{~h}$ in ethanol to completely dehydrate. The dehydrated gel particles were filtered and dried in an oven at $50{ }^{\circ} \mathrm{C}$ for $24 \mathrm{~h}$. After grinding, the powdered superabsorbent was stored in absence of moisture and light.

\section{Metal ion sorption measurement}

Salep-g-PAA (0.100 g) was added to metal chloride solutions (2000 ppm) prepared in a phosphate buffer ( $\mathrm{pH} 7)$. The mixture was shaken for $5 \mathrm{~h}$ by a rotary shaker to reach equilibrium. An exact amount of the supernatant $(5.0 \mathrm{~mL})$ was pipetted for metal ion measurements. The initial and final concentrations of metal ion were determined by the atomic absorption spectroscopy.

\section{Preparation of $\alpha-\mathrm{Fe}_{2} \mathrm{O}_{3}$ nanoparticles}

Typical synthetic procedure is as follows. $\mathrm{FeCl}_{3} \cdot 6 \mathrm{H}_{2} \mathrm{O}$ $(0.40 \mathrm{~g})$ and salep-g-PAA (0.80 g) were suspended in
$150 \mathrm{~mL}$ of distilled water. The suspension was stirred at room temperature for $5 \mathrm{~h}$. The decantation and freeze drying of the red suspension yielded a red powder which was heated at $600{ }^{\circ} \mathrm{C}$ for $8 \mathrm{~h}$. Finally the product was washed with water and hexane.

\section{Results and Discussion}

\section{Mechanism of the salep-g-PAA nanopolymer formation}

A simple procedure for polymerization of salep-g-PAA in the thermal condition is suggested in Scheme 1. The sulfate anion-radical produced by thermal decomposition of APS subtracts hydrogen from the salep to form corresponding radical. Then, the resulting macroradical initiates graft copolymerization of AA. Since a crosslinking agent (MBA) is present in the reaction mixture, a threedimensional network results.

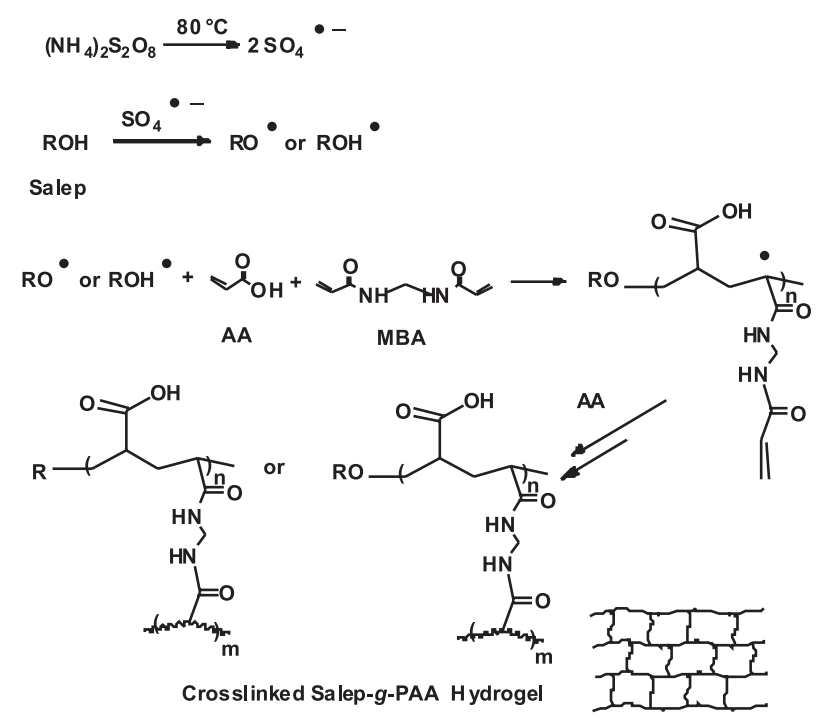

Scheme1. Outline of the synthesis of the salep-g-PAA nanopolymer.

Surface morphology of the salep-g-PAA nanopolymer

The surface structure of the nanopolymer was observed using SEM. The SEM image of salep-g-PAA sample shows a porous structure. Another interesting point in these SEM images is the relationship between porosity and water absorbency of samples in the distilled water. The salep-g-PAA sample has an highly nanoporous and cellular structure. As shown in Figure 1 the size of porosity for this hydrogel is in the range of nanometer scale (20-80 nm). To the best of our knowledge, this kind of porosity in the structure of a polysaccharide-g-PAA is rare. This result shows that smaller structures with the higher porosity can lead to a higher capacity for metal entrapment. 


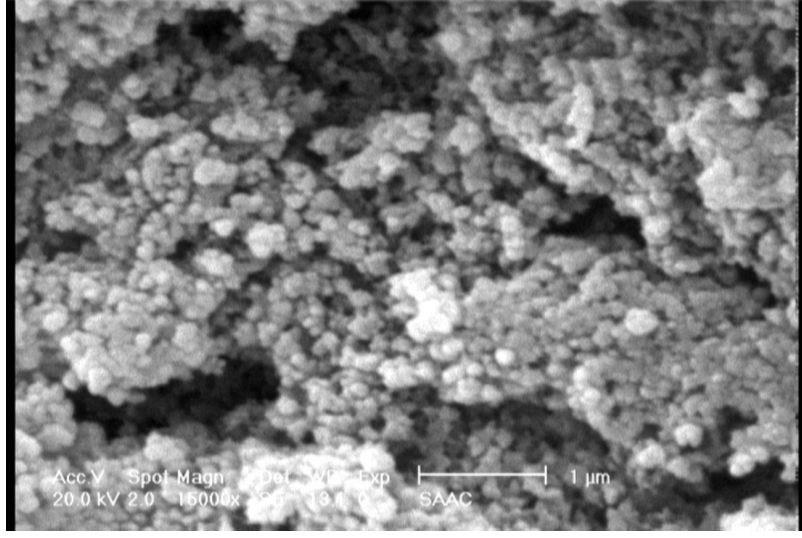

Figure 1. SEM photograph of salep-g-PAA.

\section{Studies on entrapment of metal ions}

The binding properties of a series of metal ions such as $\mathrm{Fe}^{3+}, \mathrm{Cu}^{2+}, \mathrm{Co}^{2+}$ and $\mathrm{Ni}^{2+}$ with salep-g-PAA nanopolymer were determined. The iron ion sorption capacity was the highest with $1.9 \mathrm{mmol} \mathrm{g}^{-1}$. The sorption capacities of iron, copper, cobalt and nickel ions are presented in Figure 2.

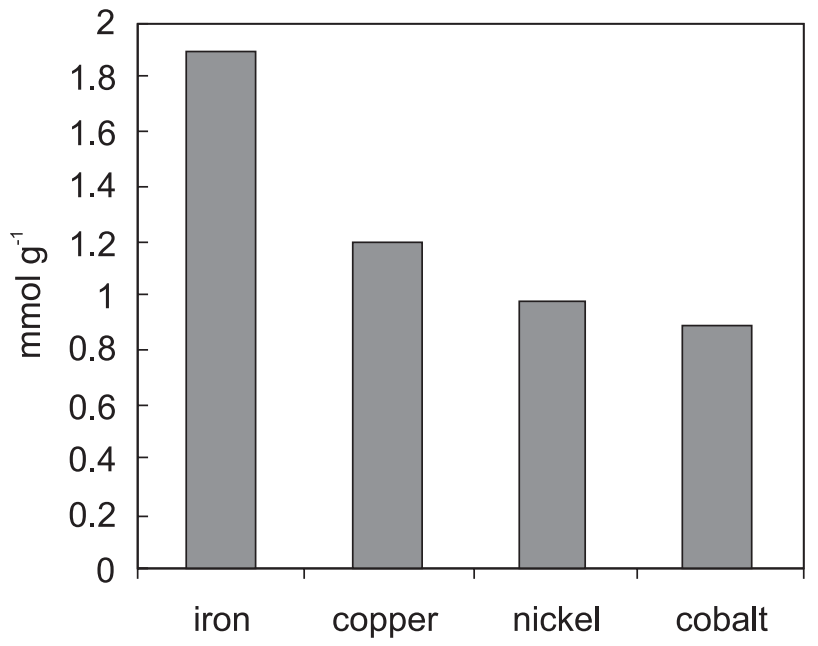

Figure 2. The sorption capacities of salep-g-PAA nanopolymer for $\mathrm{Fe}^{3+}$, $\mathrm{Cu}^{2+}, \mathrm{Co}^{2+}$ and $\mathrm{Ni}^{2+}$ ions.

The characterizations of $\alpha-\mathrm{Fe}_{2} \mathrm{O}_{3}$ nanoparticles

Figure 3 shows XRD patterns of the $\alpha-\mathrm{Fe}_{2} \mathrm{O}_{3}$ nanoparticles. Nine characteristic peaks were observed for $\alpha-\mathrm{Fe}_{2} \mathrm{O}_{3}$ nanoparticles $\left(2 \theta=24.2^{\circ}, 33.1^{\circ}, 35.7^{\circ}\right.$, $41.0^{\circ}, 49.6^{\circ}, 54.2^{\circ}, 57.5^{\circ}, 62.5^{\circ}$, and $\left.64.1^{\circ}\right)$ marked by their indices ((012), (104), (110), (113), (024), (116), (018), (214), (300)). According to these patterns the optimized decomposition time for the synthesis of $\alpha-\mathrm{Fe}_{2} \mathrm{O}_{3}$ nanoparticles is $8 \mathrm{~h}$. A mixture of $\mathrm{Fe}_{2} \mathrm{O}_{3}$ and $\mathrm{Fe}_{3} \mathrm{O}_{4}$ was obtained when decomposition time of salep-g-PAA decreases to $4 \mathrm{~h}$ (Figure 3 sample B). The average crystallite size was calculated for the $\alpha-\mathrm{Fe}_{2} \mathrm{O}_{3}$ nanoparticles using the Scherrer's equation on the reflections with (104), (110) and (116). The average crystallite size of nanoparticles was found to be about $30 \mathrm{~nm}$. The smaller particles of the $\alpha-\mathrm{Fe}_{2} \mathrm{O}_{3}$ and its high purity are the significant advantages of this approach.
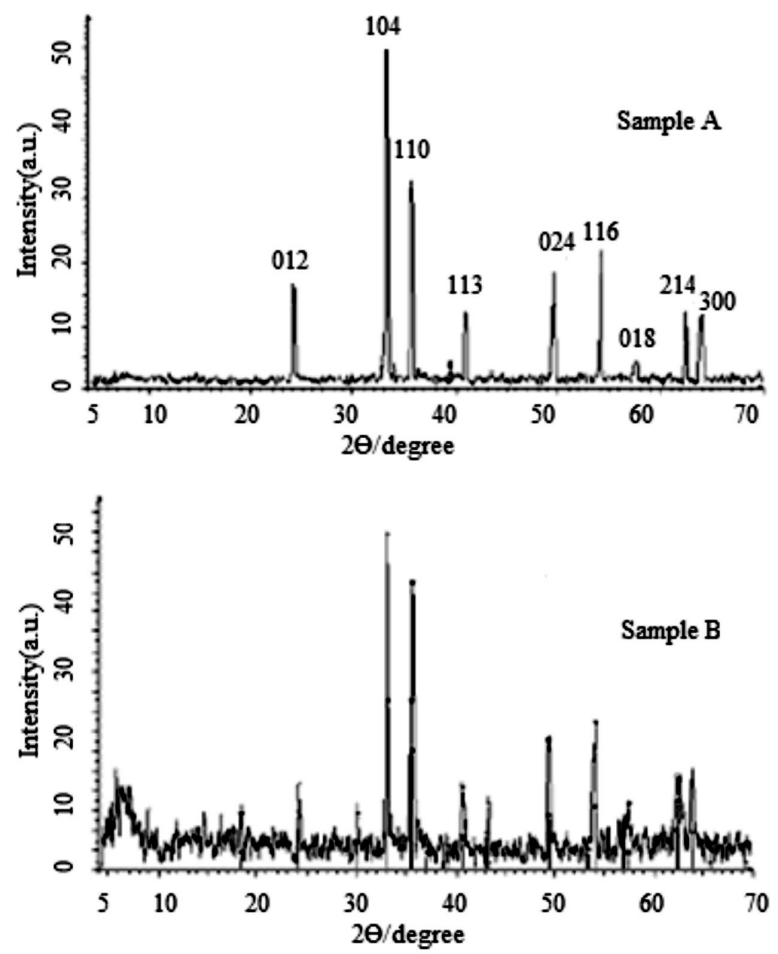

Figure 3. XRD patterns of the $\alpha-\mathrm{Fe}_{2} \mathrm{O}_{3}$ nanoparticles (sample A, decomposition time: $8 \mathrm{~h}$, and sample $\mathrm{B}$, decomposition time: $4 \mathrm{~h}$ ).

Figure 4 shows the FT-IR spectra of (a) the pure salepg-PAA, (b) the $\mathrm{Fe}^{3+}$-contained salep-g-PAA $\left(\mathrm{SAP} \Rightarrow \mathrm{Fe}^{3+}\right.$ ) and (c) pure $\alpha-\mathrm{Fe}_{2} \mathrm{O}_{3}$ nanoparticles. Comparison of the spectra (a) and (b) shows that the carbonyl peak position in the $\mathrm{SAP} \Rightarrow \mathrm{Fe}^{3+}$ is shifted to a higher wavenumber $\left(1718.3 \mathrm{~cm}^{-1}\right.$ to $\left.1731.1 \mathrm{~cm}^{-1}\right)$. This suggests that an interaction should exist between the carboxyl groups of salep-g-PAA with the $\mathrm{Fe}^{3+}$ ions. Finally, the spectrum (c) shows that the pure $\alpha-\mathrm{Fe}_{2} \mathrm{O}_{3}$ nanoparticles were obtained by thermal decomposition of SAP $\Rightarrow \mathrm{Fe}^{3+}$. The absorption bands at 564 and $578 \mathrm{~cm}^{-1}$ pertains to the stretching vibrational mode of $\mathrm{Fe}-\mathrm{O}$ bond. ${ }^{26}$

Figure 5 illustrates the TEM images of $\alpha-\mathrm{Fe}_{2} \mathrm{O}_{3}$ nanoparticles. One can find that the morphology of $\alpha-\mathrm{Fe}_{2} \mathrm{O}_{3}$ nanoparticles is a hexagonal plate. Narrow distribution of the size of particles $(20-80 \mathrm{~nm})$ and the regular distribution of $\alpha-\mathrm{Fe}_{2} \mathrm{O}_{3}$ nanoparticles are attributed to the use of salep-g-PAA nanopolymer as the coating agent (Figure 5d). 


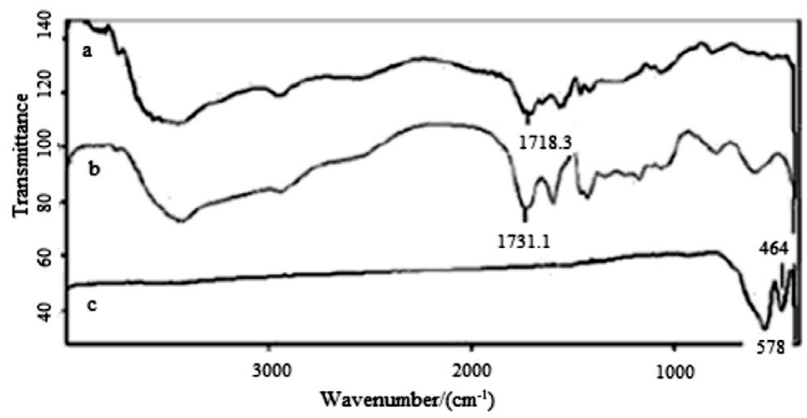

Figure 4. FT-IR spectra (a: neat salep-g-PAA, b: the $\mathrm{SAP} \Rightarrow \mathrm{Fe}^{3+}, \mathrm{c}: \alpha-\mathrm{Fe}_{2} \mathrm{O}_{3}$ nanoparticles after decomposition).

These results indicate the superabsorbent nanopolymer with hydroxide and carboxylic acid functional groups has high binding affinity for $\mathrm{Fe}^{3+}$ ions. A possible chelation mechanism of salep-g-PAA nanopolymer with $\mathrm{Fe}^{3+}$ ion is shown in Figure 6.

At the nucleation stage, the formation of the $\mathrm{Fe}_{2} \mathrm{O}_{3}$ nanoparticles could be induced and confined by the cooperation of salep-g-PAA with hydroxide and carboxylic acid functional groups. At the same time, the oxidation, carbonization and gasification of salep-g-PAA will produce ultrafine carbon black in the thermal reactions system.
Such ultrafine powders with high surface area permits that the produced nanoparticles remain separated from each other. Thus, the chelation between $\mathrm{Fe}^{3+}$ ion and salep-gPAA followed by carbonization and gasification leads to production of uniform $\mathrm{Fe}_{2} \mathrm{O}_{3}$ nanoparticles.

Thermogravimetric-differential thermal analysis (TGDTA) of both salep-g-PAA and the SAP $\Rightarrow \mathrm{Fe}^{3+}$ were used to understand the details of their decomposition process in dry air. As the data shows (Figure 7 and Table 1), the $\mathrm{SAP} \Rightarrow \mathrm{Fe}^{3+}$ is more stable than salep-g-PAA. To have a better comparison between these materials from the thermal stability point of view, a useful comprehensive index of intrinsic thermal stability (ITS) was also calculated ${ }^{27,28}$ (Table 1). A high ITS value was found for the SAP $\Rightarrow \mathrm{Fe}^{3+}$ which remained stable up to quite high temperatures.

\section{Evaluation of catalytic activity of $\alpha-\mathrm{Fe}_{2} \mathrm{O}_{3}$ nanoparticles for Friedel-Crafts acylation}

The surface of metal oxides exhibits both Lewis acid and base character. ${ }^{29}$ This is characteristic of many metal oxides such as $\mathrm{TiO}_{2}, \mathrm{Al}_{2} \mathrm{O}_{3}, \mathrm{ZnO}, \mathrm{Fe}_{2} \mathrm{O}_{3}$, while they are excellent adsorbents for a wide variety of organic
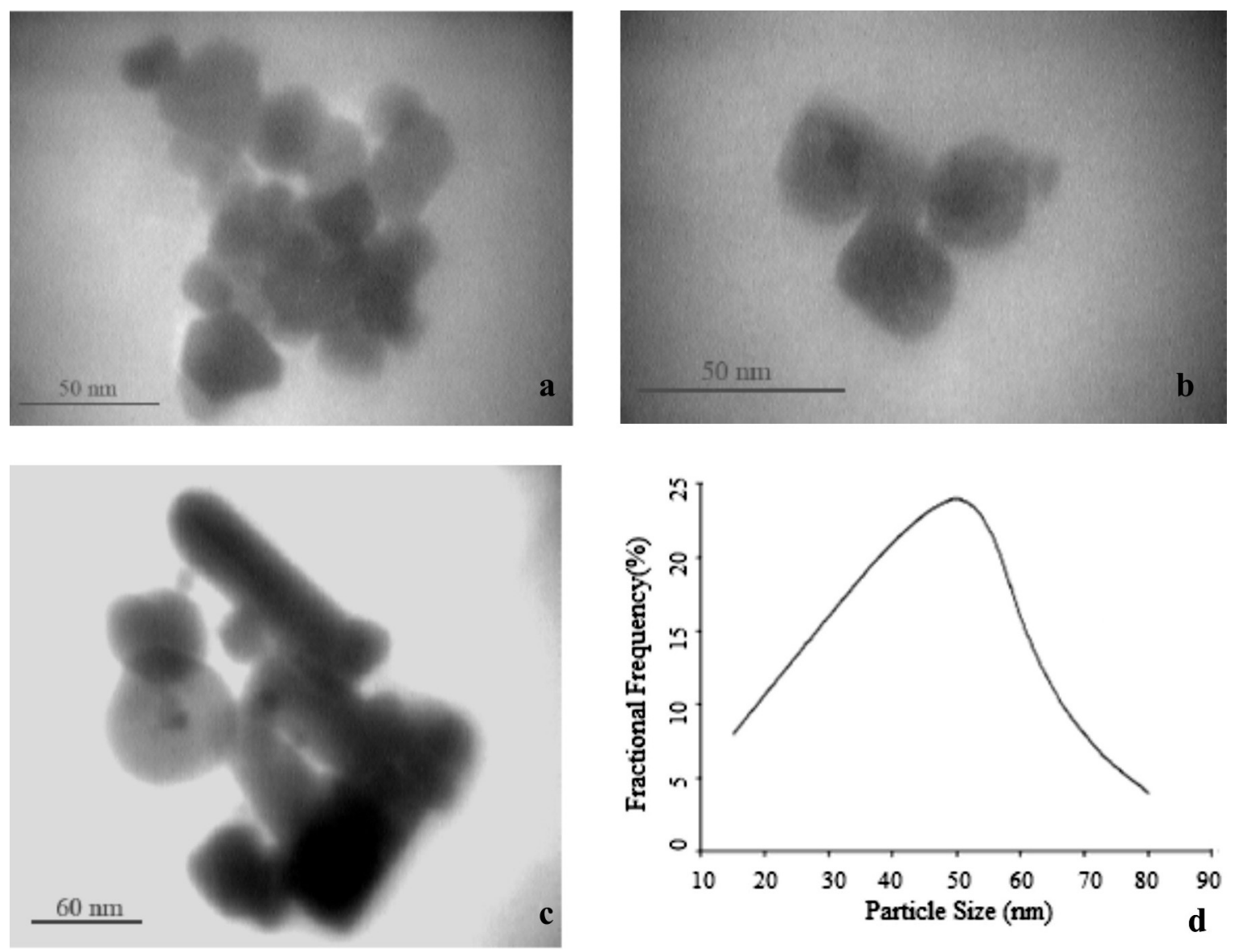

Figure 5. TEM micrographs and particle size distribution of the $\alpha-\mathrm{Fe}_{2} \mathrm{O}_{3}$ nanoparticles. 


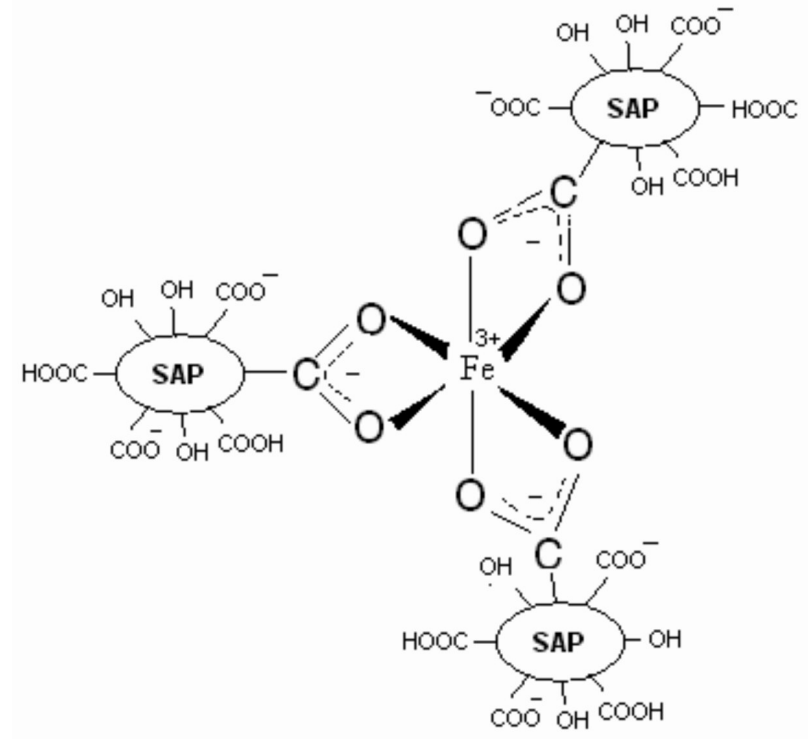

Figure 6. A possible entrapment mechanism of $\mathrm{Fe}^{3+}$ ions by the salepg-PAA nanopolymer.

compounds. ${ }^{30}$ In any metal oxide, surface atoms make a distinct contribution to its catalyst activity. In the nanopowders higher specific surface area, as compared to the bulk powders, results in the higher catalytic activity of nanopowders. Furthermore, nanopowder metal oxides find excellent applications as active adsorbents for gases, for destruction of hazardous chemicals and as catalysts for various organic transformations. ${ }^{32-33}$

To show catalytic activity of $\alpha-\mathrm{Fe}_{2} \mathrm{O}_{3}$ nanoparticles synthesized by this protocol, we examined its catalytic activity in the Friedel-Crafts acylation reaction. As a model reaction, we chose reaction of $p$-xylene with benzoyl chloride. The results show that $\alpha-\mathrm{Fe}_{2} \mathrm{O}_{3}$ nanoparticles are more efficient than the bulk $\mathrm{Fe}_{2} \mathrm{O}_{3}$ (Table 2, entries 1 and 2). The bulk $\mathrm{Fe}_{2} \mathrm{O}_{3}$ catalyzed the reaction in harsh conditions (high temperature and longer reaction time).

Several examples have been investigated and all are listed in Table 2. As shown, aromatic ketones were obtained with high yields (71-94\%) under the conditions of low mol\% catalyst ( $1 \mathrm{~mol} \%$ ), clean reaction and short reaction time $(1 \mathrm{~h})$. The structure of the products was confirmed by ${ }^{1} \mathrm{H}$ NMR, ${ }^{13} \mathrm{C}$ NMR spectra and compared with real samples prepared by reported methods. ${ }^{34}$

The applicability of the $\alpha-\mathrm{Fe}_{2} \mathrm{O}_{3}$ nanoparticles is further extended by performing the Friedel-Crafts alkylation reaction with $p$-xylene and benzyl bromide in the presence of $\alpha-\mathrm{Fe}_{2} \mathrm{O}_{3}$ nanoparticles ( $1 \mathrm{~mol} \%$ ). The reaction was performed efficiently and the reaction rate as well as the yield of product is quite satisfactory (87\%).

In conclusion, this is the first report on the synthesis of pure $\alpha-\mathrm{Fe}_{2} \mathrm{O}_{3}$ nanoparticles $(30 \mathrm{~nm}$ ) using of the superabsorbent nanopolymer (SANP) by thermal
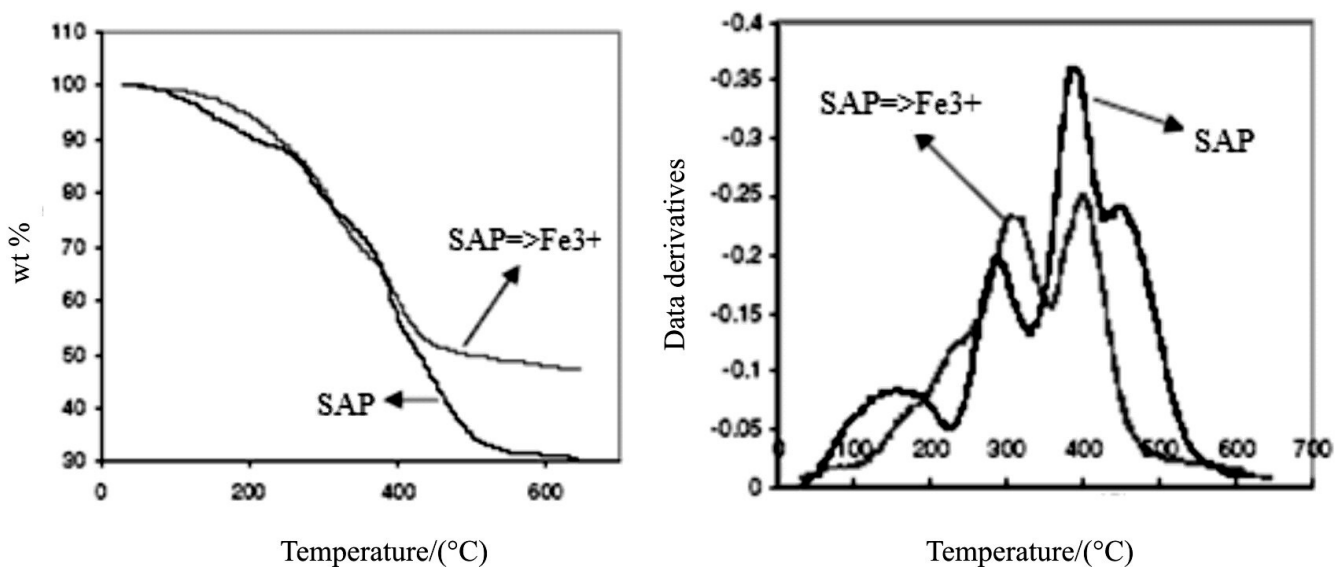

Figure 7. TG-DTG of the salep-g-PAA superabsorbent polymer (SAP) and the $\mathrm{SAP}=>\mathrm{Fe}^{3+}$.

Table 1.Thermal ${ }^{a}$ Behavior Data of the salep-g-PAA superabsorbent polymer (SAP) and the SAP $\Rightarrow \mathrm{Fe}^{3+}$

\begin{tabular}{|c|c|c|c|c|c|c|c|c|c|}
\hline \multirow[b]{2}{*}{ Polymer } & \multicolumn{3}{|c|}{ first Water loss } & \multicolumn{3}{|c|}{ Temperature $/\left({ }^{\circ} \mathrm{C}\right)$ at various wt. $\%$ losses } & \multirow[t]{2}{*}{$\mathrm{Y}^{\mathrm{c}} /(\mathrm{wt} . \%)$} & \multirow[t]{2}{*}{ IPDT $/\left({ }^{\circ} \mathrm{C}\right)$} & \multirow[t]{2}{*}{ ITS $^{e}$} \\
\hline & wt. $\%$ & $\mathrm{~T} /\left({ }^{\circ} \mathrm{C}\right)$ & $\mathrm{T}_{\mathrm{d}}^{\mathrm{b}}$ & 5 & 10 & 50 & & & \\
\hline SAP & 6.6 & 163 & 294 & 143 & 207 & 428 & 26 & 294 & 0.43 \\
\hline $\mathrm{SAP} \Rightarrow \mathrm{Fe}^{3+}$ & 4.6 & 185 & 317 & 191 & 240 & 493 & 47 & 301 & 0.44 \\
\hline
\end{tabular}

aThermal measurements were conducted using a TG system at a heating rate of $20^{\circ} \mathrm{C} \mathrm{min}^{-1}$ under nitrogen at a flow rate of $50 \mathrm{~mL} \mathrm{~min}^{-1}$; ${ }^{\mathrm{b}} \mathrm{Onset}$ temperature of initial decomposition; ${ }^{\circ} \mathrm{Char}$ yield (residual weight) at $600{ }^{\circ} \mathrm{C}$ in argon; ${ }^{d}$ Integral procedural decomposition temperature (temperature at which half the ultimate volatilization has occurred); ${ }^{\circ}$ Comprehensive index of intrinsic thermal stability. 
Table 2. The results of Friedel-Crafts acylation using the $\alpha-\mathrm{Fe}_{2} \mathrm{O}_{3}$ nanoparticles

\begin{tabular}{lcc}
\hline Entry & ArH & Yield $(\%)$ \\
\hline 1 & $p$-Xylene & 94 \\
2 & $p$-Xylene & $80^{\mathrm{a}}$ \\
3 & Benzene & 86 \\
4 & Toluene & 88 \\
5 & Bromobenzene & 71 \\
6 & Anisole & 82 \\
\hline
\end{tabular}

${ }^{a}$ Reaction conditions: bulk $\mathrm{Fe}_{2} \mathrm{O}_{3}, 150{ }^{\circ} \mathrm{C}, 10 \mathrm{~h}$.

decomposition. Inexpensiveness of the reactants and high metal sorption capacity are the advantages of polysaccharide as starting material for this method. Test of the synthesized $\alpha-\mathrm{Fe}_{2} \mathrm{O}_{3}$ nanoparticles in Friedel-Crafts acylation revealed its superior activity than the bulk $\mathrm{Fe}_{2} \mathrm{O}_{3}$.

\section{References}

1. Guardia, P.; Brugal, B. B.; Roca, A. G.; Iglesias, O.; Morales, M. P.; Serna, C. J.; Labarta, A.; Batlle, X.; J. Magn. Magn. Mater. 2007, 316, e756.

2. Hau, L.H.; Li, X. L.; Li, W.; Xi, S. Q.; Sens. Actuators, B 2000 , 71,77 .

3. Katsuki, H.; Komarneni, S.; J. Am. Ceram. Soc. 2003, 86, 183.

4. Tedeschi, L.; Enders, D.; Org. Lett. 2001, 3, 3515.

5. Shan, Z.; Yang, W.-S.; Zhang, X.; Huang, Q.-M.; Ye, H.; J. Braz. Chem. Soc. 2007, 18, 1329.

6. Chen, J.; Xu, L.; Li, W.; Gou, X.; Adv. Mater. 2005, 17, 582.

7. Cornell, R. M.; Schwertmann, U.; The Iron Oxides. Structure, Properties, Reactions, Occurrence and Uses, VCH: Weinheim, 1996.

8. Ksapabutr, B.; Gulari, E.; Wongkasemjit, S.; Mater. Chem. Phys. 2006, 99, 318.

9. Dhage, S. R.; Khollam, Y. B.; Potdar, H. S.; Deshpande, S. B.; Bakare, P. P.; Sainkar, S. R.; Date, S. K.; Mater. Lett. 2002, 57, 457.

10. Narayanaswamy, A.; Xu, H.; Pradhan, N.; Kim, M.; Peng, X.; J. Am. Chem. Soc. 2006, 128, 10310.

11. Gonzalez, M. M.; Snyder, G. J.; Prieto, A. L.; Gronsky, R.; Sands, T.; Stacy, A. M.; Nano Lett. 2003, 3, 973.
12. Silva, R.; Kunita, M. H.; Girotto, E. M.; Radovanovic, E.; Muniz, E. C.; Carvalho, G. M.; Rubira, A. F.; J. Braz. Chem. Soc. 2008, 19, 1224.

13. Mizukoshi, Y.; Seino, S.; Okitsu, K.; Kinoshita, T.; Otome, Y.; Nakagawa, T.; Yamamoto, T. A.; Ultrason. Sonochem. 2005, $12,191$.

14. Chen, X.; Zhang, Z.; Qiu, Z.; Shi, C.; Li, X.; Solid State Commun. 2006,140, 267.

15. Yang, Y.; Li, X.; Chen, J.; Chen, H.; Bao, X.; Chem. Phys. Lett. 2003, 373, 22.

16. Liu, H. L.; Ko, S. P.; Wu, J. H.; Jung, M. H.; Min, J. H.; Lee, J. H.; An, B. H.; Kim, Y. K.; J. Magn. Magn. Mater. 2007, 310, e815.

17. Lee, H. Y.; Lim, N. H.; Seo, J. A.; Khang, G.; Kim, J.; Lee, H. B.; Cho, S.H.; Polymer (Korea) 2005, 29, 266.

18. Moghaddam, F. M.; Saeidian, H.; Mater. Sci. Eng. B. 2007, 139, 265.

19. Mirjafary, Z.; Saeidian, H.; Sadeghi, A.; Moghaddam, F. M.; Catal. Commun. 2008, 9, 299.

20. Pourjavadi, A.; Barzegar, Sh.; Zeidabadi, F.; React. Funct. Polym. 2007, 67, 644.

21. Pourjavadi, A.; Kurdtabar, M.; Eur. Polym. J. 2007, 43, 877.

22. Pourjavadi, A.; Barzegar, Sh.; Mahdavinia, G. R.; Carbohydr. Polym. 2006, 66, 386.

23. Zohuriaan-Mehr, M. J.; Pourjavadi, A.; Salehi-Rad, M.; React. Funct. Polym. 2004, 61, 23.

24. Pourjavadi, A.; Soleyman, R.; Bardajee, G. R.; Starch/Starke 2008, 60, 468.

25. Bardajee, G. R.; Pourjavadi, A.; Soleyman, R.; Sheikh, N.; Nucl. Instrum. Methods Phys. Res., Sect. A 2008, 2663932.

26. Serna, C. J.; Rendon, J.L.; Iglesias, J. E.; Spectrochim. Acta 1982, 38, 797.

27. Doyle, C. D.; Anal. Chem. 1961, 33, 77.

28. Pourjavadi, A.; Zamanlu, M. R.; Zohuriaan-Mehr, M. J.; J. Appl. Polym. Sci. 2000, 77, 1144.

29. Tanabe, K.; Solids and Bases, Academic Press: New York, 1970.

30. Riyas, S.; Krishnan, G.; Mohan Das, P. N.; J. Braz. Chem. Soc. 2008, 19, 1023.

31. Schlogl, R.; Abd Hamid, B. S.; Angew. Chem. Int. Ed. 2004, 43, 1628.

32. Choudary, B. M.; Kantam, M. L.; Ranganath, K.V.S.; Mahendar, K.; Sreedhar, B.; J. Am. Chem. Soc. 2004, 126, 3396.

33. Salavati-Niasari, M.; J. Mol. Catal. A: Chem. 2007, 263, 247.

34. Morley, J.O.; J. Chem. Soc., Perkins Trans. II 1977, 601.

Received: August 6, 2008 Web Release Date: February 13, 2009 